NASA Technical Memorandum 86451

Mesoscale Observations of Lightning From Space Shuttle

B. Vonnegut, O. H. Vaughan, Jr.,

M. Brook, and P. Krehbiel

SEPT TMBEIRT 198: 
NASA Technical Memorandum 86451

\section{Mesoscale Observations of Lightning From Space Shuttle}

B. Vonnegut

State University of New York at Albany

Albany, New York

O. H. Vaughan, Jr.

George C. Marshall Space Flight Center

Marshall Space Flight Center, Alabama

M. Brook and P. Krehbiel

New Mexico Institute of Mining and Technology

Socorro, New Mexico

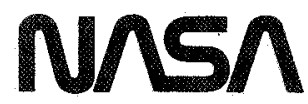

National Aeronautics and Space Administration

Scientific and Technical

Information Branch

1984 



\section{ACKNOWLEDGMENTS}

The successful conduct of the experiments reported here required the efforts and cooperation of many more individuals and groups than is usual in most scientific studies. Foremost among those to whom we are indebted are the astronauts, Commander J. H. Engle and Pilot R. H. Truly of STS-2, Commander T. K. Mattingly II and Pilot $\mathrm{H}$. W. Hartsfield, Jr., of STS-4, and Commander P. Weitz and Pilot K. Bobko of STS-6. They succeeded in taking data on storms and lightning despite the many other duties connected with the test flights of their extraordinary new vehicle. For their contributions in providing the ground work for these experiments, integrating them into the Space Shuttle program, and coordinating efforts during the mission, we are especially indebted to the following individuals: $J$. Hughes, ONR; R. Taylor, NSF; E. Dewan, USAF; J. Dodge, NASA Headquarters; R. Baldwin, F. Brizzolara, R. Crippen, R. Curtner, R. Moke, A. Potter, R. Walter, R. Weitenhagen, R. Williamson, D. Yeates, J. Young, NASA Johnson Space Center; J. Arnold, H. Christian, P. Hassler, G. Jedlovec, B. Schrick, R. Smith, W. Vaughan, G. Wilson, NASA Marshall Space Flight Center; C. B. Moore, New Mexico Institute of Mining and Technology; L. Bosart, M. Landin, A. Landor, S. Marsh, R. Orville, State University of New York at Albany. We are grateful for the help of C. Cooper and $\mathrm{T}$. Vonnegut. We are indebted to Global Weather Center in Omaha, Nebraska, for their forecasting support during the flights. We appreciate the continuing support of the National Aeronautics and Space Administration (Contracts NAS 8-32893 and NAS 8-33817), the Office of Naval Research (Contracts N00014-80-C-0312 and N00014-84-K-0069), and the National Science Foundation (Grants ATM7921080 and ATM8117665), which made this work possible. 

TABLE OF CONTENTS

Page

INTRODUCTION $\ldots \ldots \ldots \ldots \ldots \ldots \ldots \ldots \ldots \ldots \ldots \ldots \ldots \ldots \ldots \ldots \ldots \ldots \ldots \ldots \ldots \ldots \ldots$

OBSERVATIONAL EQUIPMENT $\ldots \ldots \ldots \ldots \ldots \ldots \ldots \ldots \ldots \ldots \ldots \ldots \ldots \ldots \ldots \ldots \ldots$

OPERATIONAL PROCEDURES $\ldots \ldots \ldots \ldots \ldots \ldots \ldots \ldots \ldots \ldots \ldots \ldots \ldots \ldots \ldots \ldots \ldots \ldots . \ldots$

DAYTIME OBSERVATIONS $\ldots \ldots \ldots \ldots \ldots \ldots \ldots \ldots \ldots \ldots \ldots \ldots \ldots \ldots \ldots \ldots \ldots$

NIGHTTIME OBSERVATIONS $\ldots \ldots \ldots \ldots \ldots \ldots \ldots \ldots \ldots \ldots \ldots \ldots \ldots \ldots \ldots \ldots \ldots \ldots$

DISCUSSION $\ldots \ldots \ldots \ldots \ldots \ldots \ldots \ldots \ldots \ldots \ldots \ldots \ldots \ldots \ldots \ldots \ldots \ldots \ldots \ldots \ldots \ldots$

CONCLUSIONS $\ldots \ldots \ldots \ldots \ldots \ldots \ldots \ldots \ldots \ldots \ldots \ldots \ldots \ldots \ldots \ldots \ldots \ldots \ldots \ldots \ldots$

REFERENCES $\ldots \ldots \ldots \ldots \ldots \ldots \ldots \ldots \ldots \ldots \ldots \ldots \ldots \ldots \ldots \ldots \ldots \ldots \ldots \ldots \ldots$ 


\section{LIST OF ILLUSTRATIONS}

Figure

Title

Page

1. Instrumentation package comprising $16 \mathrm{~mm}$ motion picture camera with attached photocell optical sensor in foreground .......

2. Thunderstorm cloud system photographed in daylight by astronaut Truly during STS-2 November $1981 \ldots \ldots \ldots \ldots \ldots \ldots \ldots \ldots$

3. McIDAS imaging showing the storm over southern Brazil that produced the lightning events illustrated in Figures 4, 7, and 8 , which were photographed during orbits 22 and 23 of STS- 4

4. Images from the first nine frames of $16 \mathrm{~mm}$ film showing the development of a $\mathrm{Y}$-shaped lightning event over southern

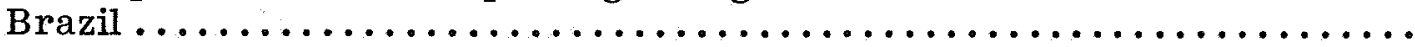

5. Sequence of three frames showing how appearance of a cumuliform cloud system changes as it is illuminated in different ways by lightning strokes that are taking place

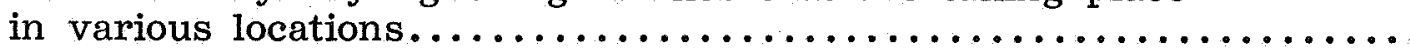

6. Lightning sequences $A$ and $B$ photographed by Astronaut

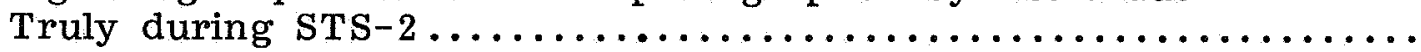

7. Lightning sequences $\mathrm{C}-\mathrm{F}$ photographed by Astronaut

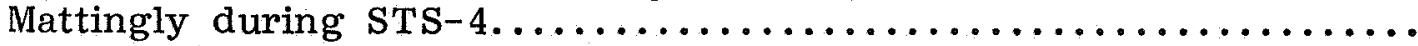

8. Lightning sequences G-I photographed by Astronaut

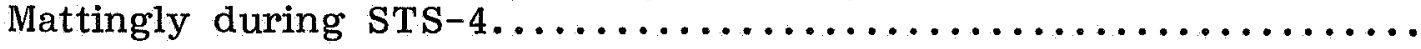


TECHNICAL MEMORANDUM

MESOSCALE OBSERVATIONS OF LIGHTNING FROM SPACE SHUTTLE

INTRODUCTION

Data from unmanned instruments flown in the space program have already contributed significantly to the understanding of atmospheric electricity . Orbiting satellites have provided new information on the frequency of lightning discharges as a function of the time of day, year, and location on the Earth's surface $[1,2,3,4]$. The Pioneer and Voyager programs have revealed that lightning discharges are not peculiar to our atmosphere, but also occur on Jupiter $[5,6]$, Venus $[7,8]$, and Saturn [9] .

It is evident from eyewitness accounts of astronauts that the view from an orbiting satellite gives a new perspective on the details of lightning discharges. Here is an example: "Looking down through moonlit clouds, Conrad could see hundreds of grass fires surrounding what he took to be villages in Africa. On all sides, lightning illuminated patches of thunderheads. He thought of his return from the moon in November of 1969, when from a distance of twenty-five thousand miles he had seen lightning flashes ripping up the entire nighttime side of the Earth" [10].

Here is another description by Astronaut Gibson of lightning he saw over the Andes, "We've just been coming over, in the past five minutes, an extensive area of thunderstorms . . . There seems to be some sort of a collective organization to the lightning strikes which occur over a wide area. When one goes off, two or three may go off simultaneously, or that one may turn out to trigger a whole lot of other ones all over a very wide area - five hundred thousand square miles, perhaps. The lightning flashes then will go off, numerous ones - ten, twenty, forty, fifty. It'd be calm again for about 1 to 2 seconds, then we'd get another period of - oh, maybe three, four, five maybe up to seven seconds or so of lightning going off in all locations. And it subsides; period of calm; then cycle through that again. A few things which impressed me here: One is the fact that they could go off simultaneously or near simultaneously over a large distance - sympathetic lightning bolts, if you will, analogous to sympathetic flares on the sun. And that we do get periods of calm between periods of very high activity. Some sort of collective phenomenon appears to be at work."

These observations, though surprising, are not entirely unexpected. It has been recognized from ground based radar and visual observations that lightning discharges can on occasion extend over distances as great as $100 \mathrm{~km}$ or more [11,12]. Furthermore, it has been noted that lightning sometimes seems to occur almost simultaneously at locations that are separated by many kilometers [13]. However, these limited observations made from the Earth's surface are greatly extended by the astronaut reports quoted above and others, such as that of Weitz [14], who saw discharges two or three hundred $\mathrm{km}$ long over Africa. The comprehensive new view that is available from a satellite shows that lightning events can be so extensive and highly organized that they deserve to be considered as a mesoscale meteorological phenomenon.

The foregoing descriptions raise interesting questions concerning the speed of propagation of long horizontal discharges and the possible coupling that may exist between widely separated lightning events. In order to obtain quantitative data 
concerning these processes and to explore the potentialities of thunderstorm studies from low altitude orbiting satellites, it was proposed to the National Aeronautics and Space Administration (NASA) that astronauts carry out further lightning observations during the early flights of the Space Shuttle program. Arrangements were made for a small, crew-operated experiment, which was called Night-time/Daytime Optical Survey of Lightning (NOSL). It was flown on the Space Shuttle Columbia on STS-2 as part of the OSTA-1 payload $[15,16,17]$ and on the fourth flight (STS-4) [18] . Its final flight was on the maiden voyage of the Space Shuttle Challenger (STS-6). The design of this experiment and the results that were obtained are discussed in the following sections.

\section{OBSERVATIONAL EQUIPMENT}

A hand-held, $16 \mathrm{~mm}$, cine NASA data acquisition camera was chosen as the primary device to be used by the astronauts for recording thunderstorms. Its purpose was to obtain permanent, quantitative photographic records of lightning events and the cloud systems producing them. The motion pictures taken in daytime provide valuable records of the size and structure of the convective cloud systems. It is not to be expected, however, that photographs of thunderstorms by day could reveal lightning against the bright background of clouds illuminated by sunlight. Pictures obtained at night provide a record of the geometry, areal extent, rate of propagation, and duration of lightning discharges that can be used to make analyses of the mechanism and rate of growth of the dielectric breakdown process. In some instances, the lightning photos reveal characteristics sufficient to identify lightning flashes to ground. If sufficient illumination is available from lightning or from moonlight, photographs at night can also give information on the character and extent of the cloud systems that are producing the lightning.

To supplement the records obtained on the photographic film, a photocell optical detection system was attached to the camera so that it viewed the same scene (Fig. 1). This device, which consists of a Fresnel lens that forms an image on a photocell, converts optical transients produced by lightning into electric signals that are recorded on a cassette recorder $[19,20]$. The system is capable of recording optical transients produced by lightning even against the bright background of a sunlit cloud because it responds only to the time rate of change of illumination and not to its unvarying component. It therefore can record the optical impulses of lightning either by day or by night. Furthermore, in contrast to the cine camera whose shutter is open only 40 percent of the time during its operation, the photocell provides a continuous record of lightning activity.

It should be noted that the equipment used on the Shuttle to sense and to record the optical transients produced by lightning is primitive in comparison with the similar apparatus that was subsequently developed and used for measurements from a U-2 aircraft [21]. The light gathering capability of the Fresnel lens is only one-third that of the open cell used on the U-2, and the area of the photocell is only one-third that used on the U-2. As a result, the sensitivity of the apparatus used on the Shuttle was at least an order of magnitude less than that of the U-2 system. This difference is significant because the optical signal is at least three orders of magnitude smaller at Shuttle altitude. Further limitations are imposed by the SONY TC124 recorder used to record the optical signal. In contrast to the wideband II electronics of the recorder used on the U-2, this device, intended only for entertainment purposes, had a frequency response of 50 to $10,000 \mathrm{~Hz}$. 


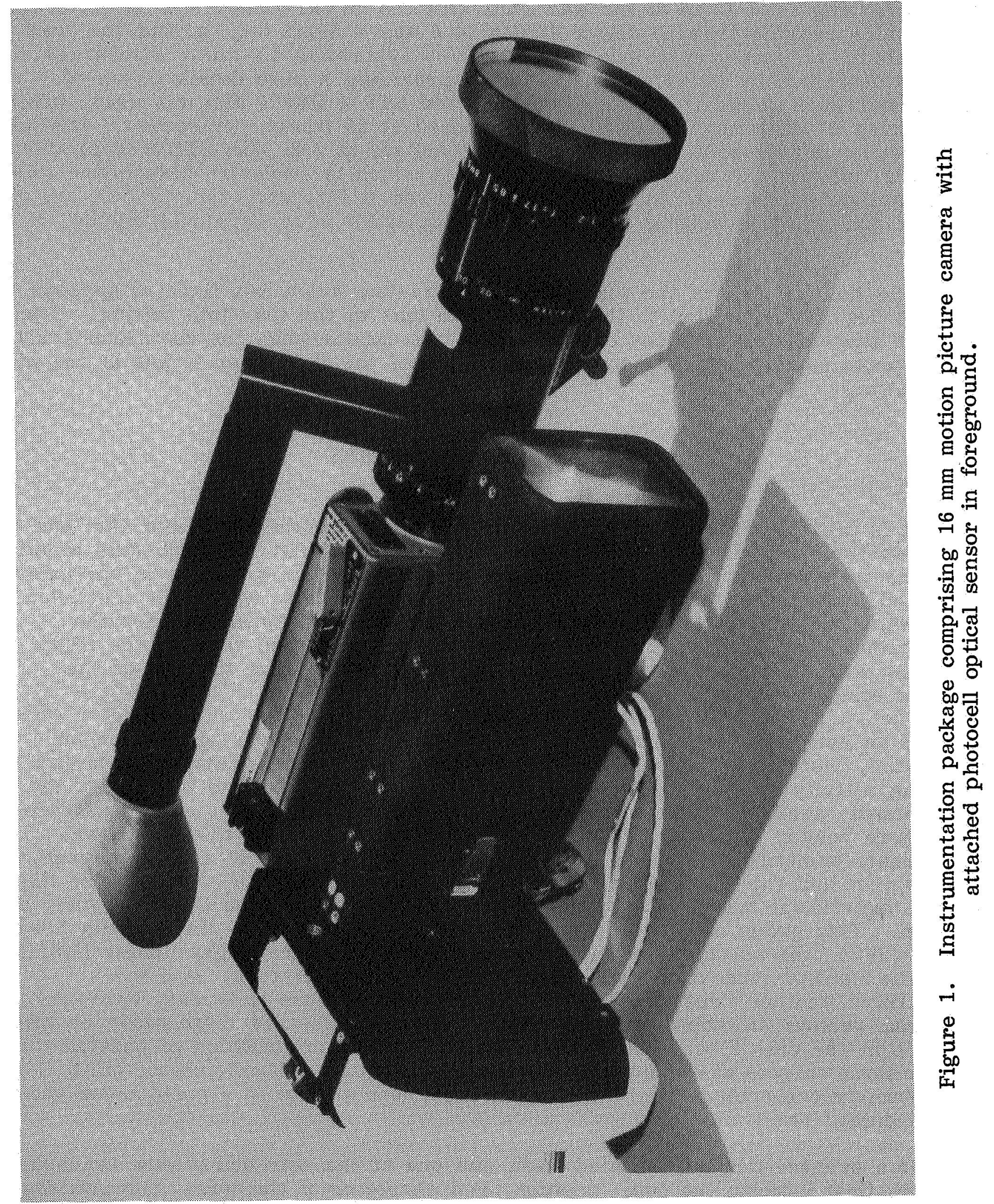


A reflex, zoom lens having an aperture ranging from $f / 2.0$ to $f / 16$ and focal lengths ranging from 17 to $85 \mathrm{~mm}$ was used with the $16 \mathrm{~mm}$ camera. This provided a field of view ranging from $32 \mathrm{deg} \times 24 \mathrm{deg}$ to $6 \mathrm{deg} \times 4-1 / 2 \mathrm{deg}$, giving the crew the capability of photographing large-scale cloud systems or lightning discharges such as those described by previous astronauts or providing a more detailed view of smaller individual thunderstorms. On STS-2 and STS-4 QX824 film was used, which is similar to Ektachrome ASA 64. It was exposed at 24 frames per second. Daylight exposure was $1 / 500 \mathrm{sec}$ at $\mathrm{f} / 8$, and at night $1 / 60 \mathrm{sec}$ at $\mathrm{f} / 2$. On $\mathrm{STS}-6$ to provide greater sensitivity, Kodak SO489 film was used, which is similar to Ektachrome ASA 400. Daylight exposure of this film was $1 / 1000$ sec at $\mathrm{f} 16$, and at night $1 / 60$ sec at $\mathrm{f} / 2$. At the nighttime setting the shutter was open for $16 \mathrm{msec}$ and closed for $26 \mathrm{msec}$.

The field of view of the photocell optical system which was fixed at approximately $6 \mathrm{deg}$, corresponded to that of the zoom lens in the telephoto setting. The photocell therefore covered the entire field of the camera when the zoom lens was in the telephoto setting and only the central region of the field when it was in the wide angle setting.

\section{OPERATIONAL PROCEDURES}

It is difficult to forecast when and where thunderstorms will occur that can be seen from the Space Shuttle. Therefore, it was planned that the astronauts would take data with the equipment when thunderstorm and lightning targets of opportunity presented themselves, providing that this would not interfere with their scheduled activities. The only time in the crew activity plan specifically allotted for the thunderstorm observation experiment was an interval of $20 \mathrm{~min}$ early in the flight to unstow and assemble the apparatus and a similar period near the end of the flight to restow it before landing.

If an astronaut were free to spend most of his time observing atmospheric phenomena, there is little doubt that he could see and evaluate thunderstorm and lightning activity in far greater detail than is possible for someone using only the data normally available to meteorologists on the ground. However, since the astronauts were heavily involved with other activities, provision was made in these experiments to notify them when they would pass over regions of strong convective activity that had the potential to produce lightning. During the course of the flight, a NOSL experiment team was stationed in the Payloads Operations Control Center at Houston. This group with the help of the meteorological staff at the Johnson Space Center (JSC), the atmospheric science team at Marshall Space Flight Center (MSFC) using the McIDAS (Man-computer Interactive Data Access System) and the USAF Global Weather Central group at Offutt Air Force Base in Omaha, Nebraska, monitored weather situations over the globe. When it appeared there might be time available in the crew's schedule to take pictures, they were notified of possible thunderstorm targets of opportunity through Space Shuttle Communicator (CAP COM) approximately one orbit $(90 \mathrm{~min})$ before the vehicle would be in a position for them to take data.

If a suitable target presented itself and one of the astronauts were available, he would first indicate the time, position, and character of the target through the microphone on the tape recorder, and then turn on the camera. In daylight he would 
begin photography using the wide-angle lens setting to show the overall meteorological situation. He could then, if he desired, change to a normal or to a telephoto setting to show details of the thunderstorm's cloud structure.

It is more difficult to take pictures of thunderstorms during the night than during the day. It is impossible to know when and where the next lightning will occur, and there are usually no fixed lights or landmarks that can be used to position the camera. With a telephoto or even a normal lens, which have rather small fields of view, the chances of securing photographs are small unless the lightning is frequent or extends over a large area. As a consequence, most nocturnal lightning photography was carried out by using the wide angle setting of the lens and pointing the camera in the general direction of the more recent flashes. The camera was run so long as a suitable target was in the field of view, usually for a period of 1 to 3 min.

\section{DAYTIME OBSERVATIONS}

Astronauts on all three flights of the Space Shuttle succeeded in obtaining beautiful photographs of convective storm systems on the sunlit side of the Earth. These show finer details of cloud structure than can be resolved in the GOES satellite pictures. The cloud structure is revealed in greatest detail when the sun approaches the horizon and casts shadows of the convective elements.

It has been hoped it might be possible through detailed examination of the photographs to follow convective motions in the cloud tops. This, however, was not the case. Because any cloud scene can be photographed for only a minute or two and because the view of the clouds is constantly changing as the result of vehicle motion, it is difficult to identify small cloud features that can be used to establish convective motions.

The successive frames of the $16 \mathrm{~mm}$ camera showing the cloud structure as seen from different positions in space can be utilized for stereo viewing. When frames separated by 5 or $10 \mathrm{sec}$ are viewed as stereo pairs, they provide a three-dimensional view of the cloud structure that reveals details not apparent in the single frames. Although the orientation of the camera is not accurately known, it would be possible by photogrammetric analysis to secure semiquantitative data on the three-dimensional structure of the clouds.

On STS-2, November 1981, daylight photographs of interesting storm cloud systems were obtained. One of these frames, illustrated in Figure 2, was taken during a 2-min period of filming. In this brief interval no pulses attributable to lightning were identified.

On STS-4, June, July, 1982, a total of 10.5 min of film was exposed during daylight, most of it of large storm systems $1,000 \mathrm{~km}$ or more from the spacecraft. Only one pulse that could clearly be identified as lightning was recorded by the photocell optical system. On STS-6, April 1983, a total of $7 \mathrm{~min}$ of film was exposed during the day of strong convective thundercloud cells over the Gulf Coast of the U.S. Many optical pulses produced by lightning were noted during this period. 


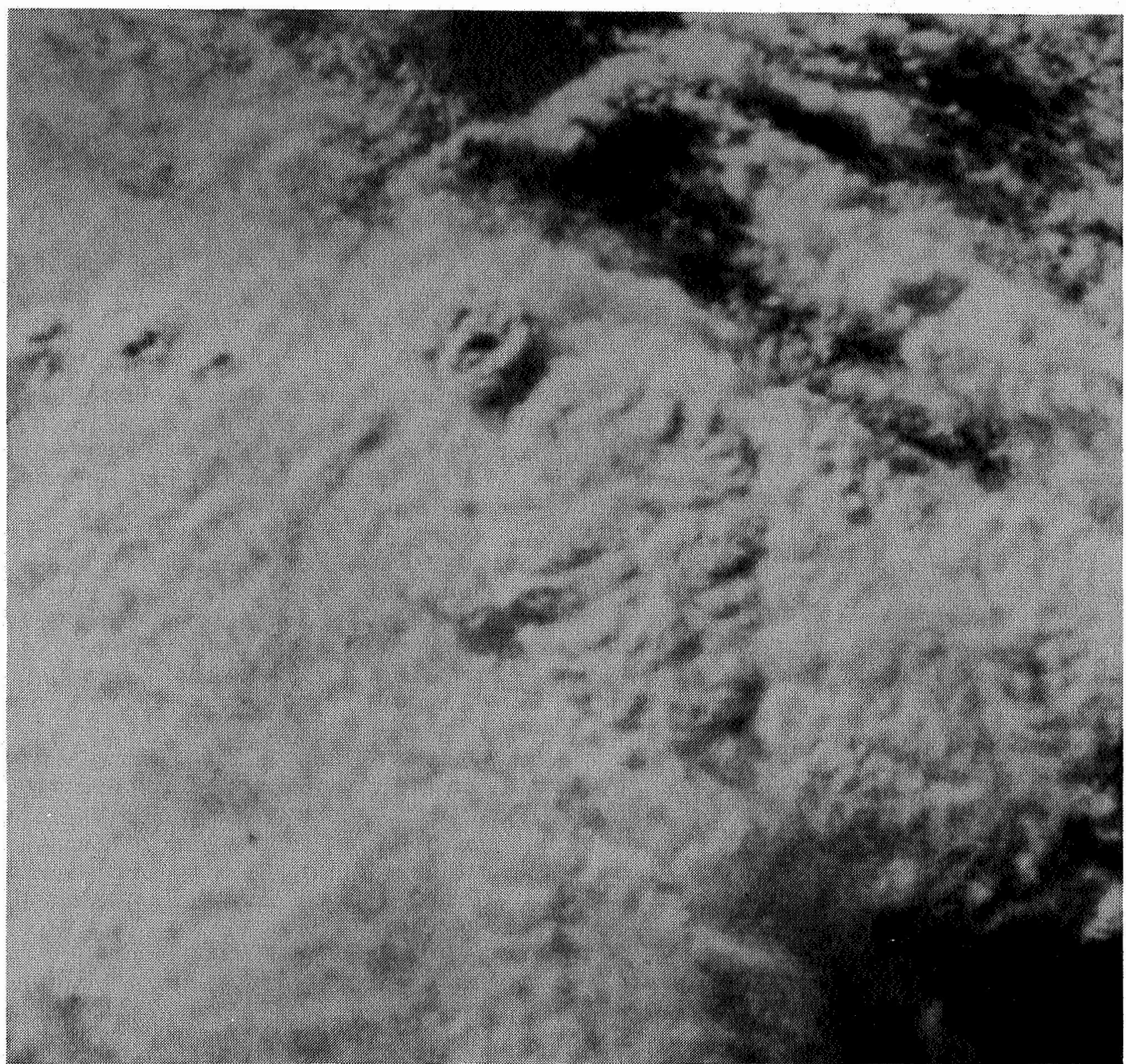

Figure 2. Thunderstorm cloud system photographed in daylight by Astronaut Truly during STS-2 November 1981. 


\section{NIGHTTIME OBSERVATIONS}

Nocturnal lightning events can be recognized on the $16 \mathrm{~mm}$ photographic film. These are the bright areas, undoubtedly clouds illuminated by lightning, that repeatedly appear in about the same position on several successive frames. The first pictures of lightning from the Space Shuttle were taken by Astronaut Truly on STS-2 during a period of little more than a minute. As the Columbia passed over South Africa at an altitude of $260 \mathrm{~km}$ on 13 November 1981 at $20: 18$ GMT on orbit 20, he photographed several lightning discharges that were occurring at the rate of a few flashes per minute in a thunderstorm some distance away from the Space Shuttle's track. The images on the film were small, only a few tenths of a millimeter.

The lightning events photographed from an altitude of $300 \mathrm{~km}$ by astronauts Mattingly and Hartsfield over a period of $10 \mathrm{~min}$, during STS-4, made larger images and lasted for longer times. The illuminated areas on the frames of the film were sometimes as big as $5 \mathrm{~mm}$. In one case they continued to appear for 40 frames, corresponding to a time interval of $1.6 \mathrm{sec}$. This storm over the southern portion of Brazil, which was photographed on 28 June 1982 at 23:18-23:21 GMT on orbit 22 and on 29 June at 00:52-00:58 GMT on orbit 23, is illustrated in the McIDAS picture shown in Figure 3. Superimposed on this photograph are the tracks of the Columbia during orbits 22 and 23. The first 9 frames of one of the more spectacular of these lightning events, which initially developed into a Y-shaped pattern, is illustrated in Figure 4. (These pictures are reproduced in greater detail in Reference 18.)

Ten minutes of film were exposed at night from Challenger on STS-6 at an altitude of $280 \mathrm{~km}$. The most interesting sequence, which is shown in Figure 5 , occurred during a 2-min period filmed at 22:15 GMT, 5 April 1983. Because the lens was in the telephoto position, small details of cloud structure can be recognized in successive frames that are too small to be resolved in the other pictures, all of which were taken with the wide-angle setting.

It is to be expected that images of stars, fires, or lights on the ground would sometimes appear in the photographs, but none was observed on film taken during the NOSL experiments. Mattingly and Hartsfield commented on impressive displays of electric lights in cities they saw at night over South America, but they took no photographs at that time.

There is wide variation in the color of the lightning images on the film. The discharges photographed on STS-2 were white. On STS-4 the colors ranged from orange or yellow to almost white for the brightly illuminated areas, while the color changed to deep red in the case of the more faint images. On STS-6 the lightning illuminated clouds such as those shown in Figure 5 were either white or bluish white in color, quite similar to those taken from a U-2 airplane [22].

In the film taken on each of the three flights, single small bright spots occasionally appear on isolated frames of the film. It is conceivable that these small, bright dots may be the images of brief single lightning flashes but much more likely that they are occasional defects in the film emulsion. In none of the photographs taken thus far from the Shuttle has it been possible to make identification of a lightning channel.

Caution must be exercised in the interpretation of the brightness and extent of the images on the film. Not only does the brightness, and hence the extent, of the images depend on the intensity, duration, and depth of the lightning in the cloud, 


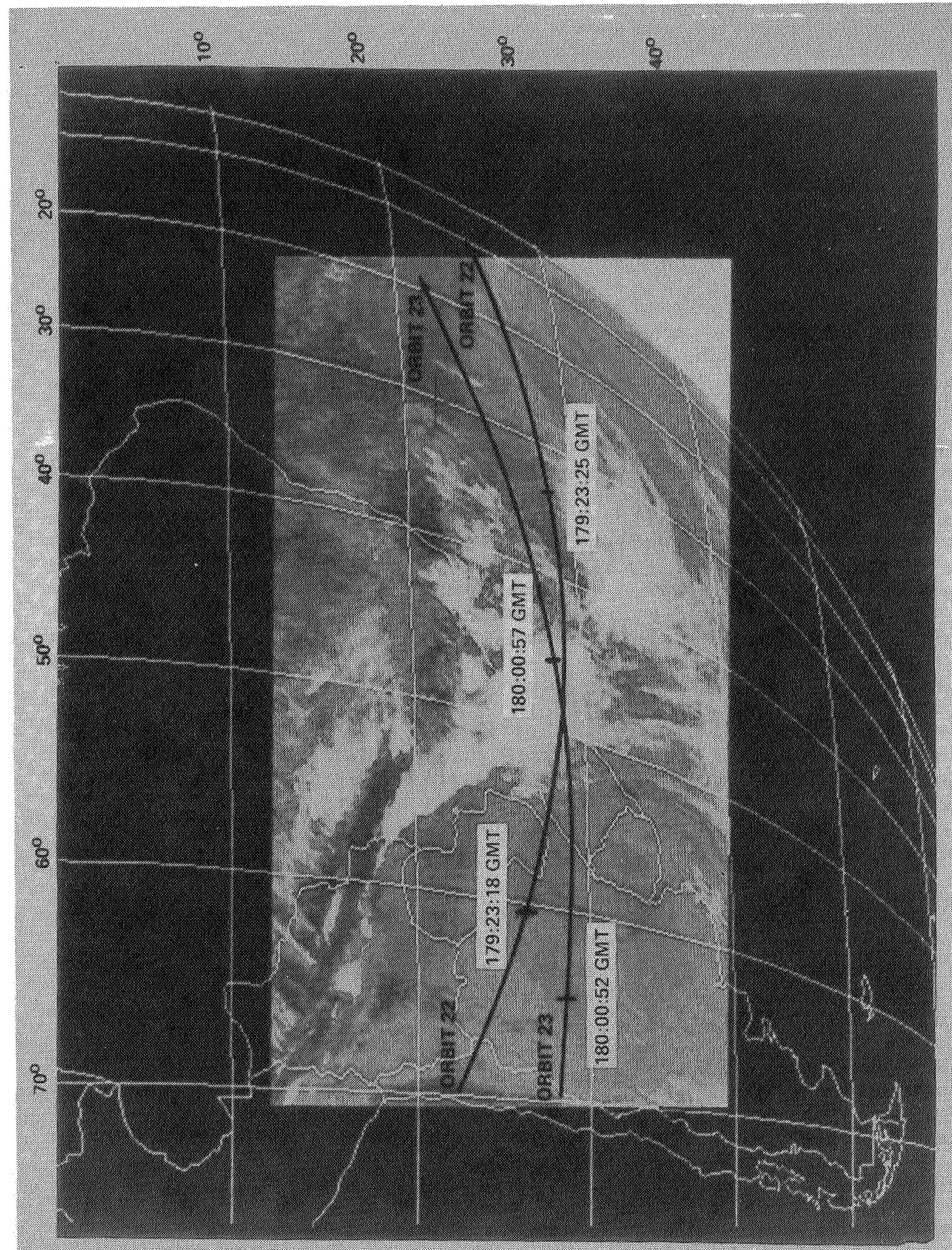

竎

ס

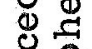

今

\%

40

+ 잉

进

$+0$

实

๘

ติ ك

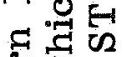

它

. 0

胥

ర్ర

द वृ ซ్ర

ฮ ส

吕

E

造 记

的

过

的

卑.

万

运 $\frac{\Phi}{\sigma}$

$0 \stackrel{5}{5}$

on

沓刍

记

制

웡

$\frac{O}{2}$

ம்

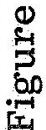




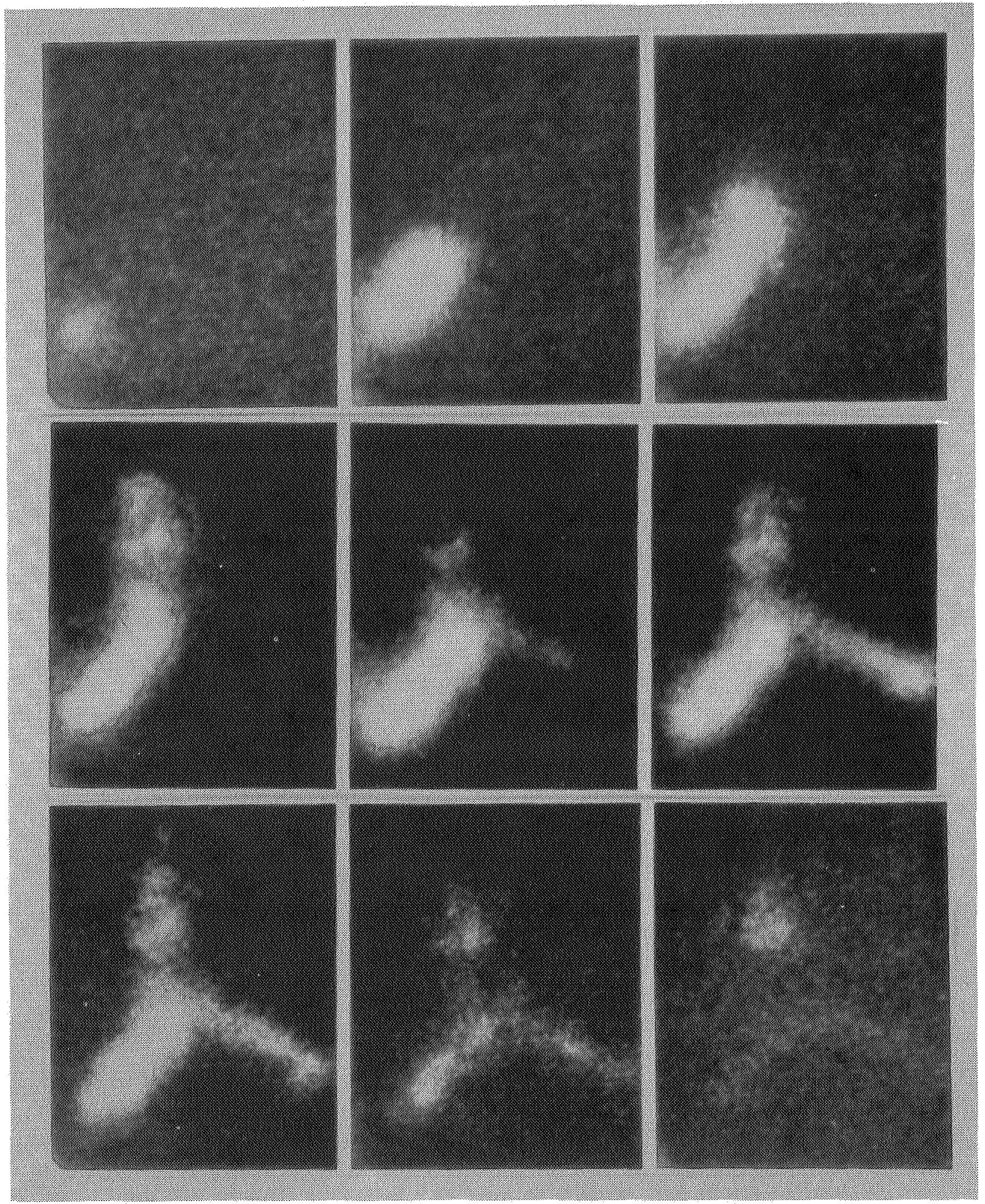

Figure 4. Images from the first nine frames of $16 \mathrm{~mm}$ film showing the development of a $\mathrm{Y}$-shaped lightning event over southern Brazil. The dimensions of the $Y$-shaped pattern are at least $60 \times 40 \mathrm{~km}$. 

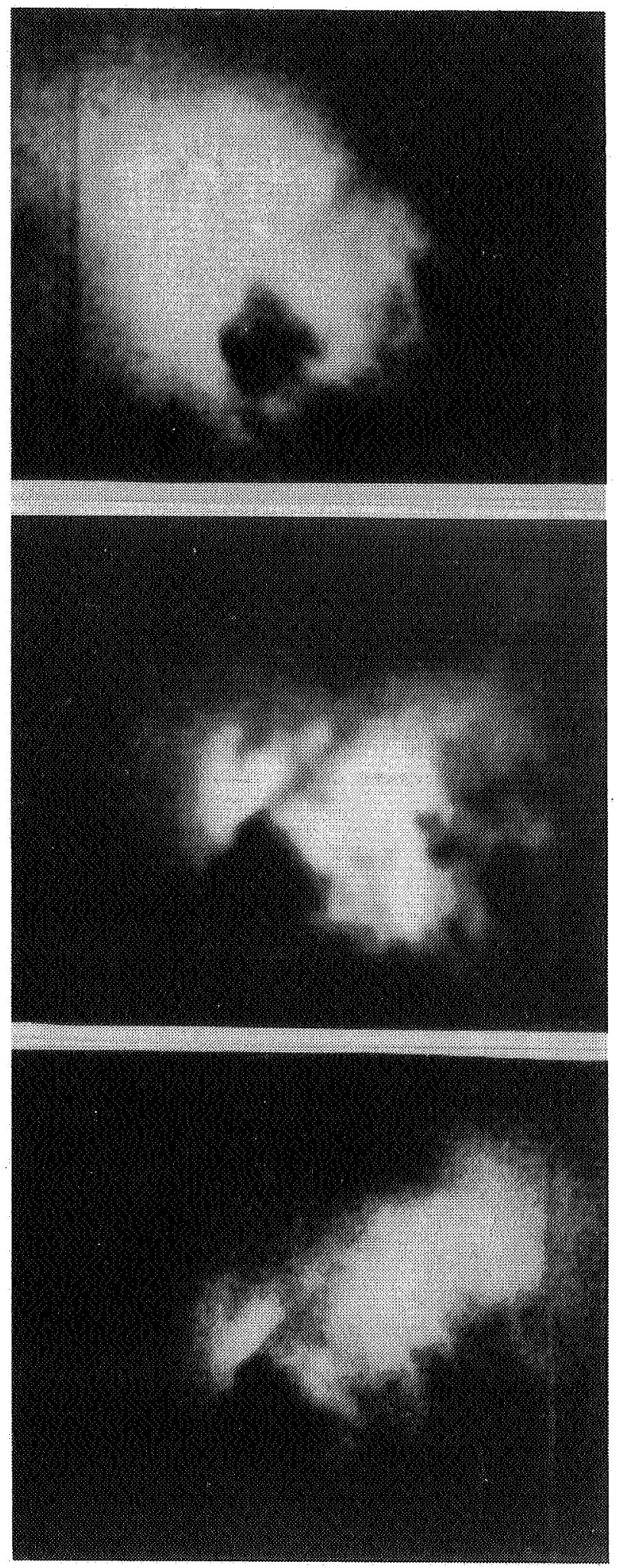

Figure 5. Sequence of three frames showing how appearance of a cumuliform cloud system changes as it is illuminated in different ways by lightning strokes that are taking place in various locations. Photographs were taken from STS-6 with lens in telephoto setting. Maximum dimensions of illuminated areas is approximately $10 \mathrm{~km}$. 
but it also depends on other factors. With the 24 per second framing rate of the camera, the shutter is open for approximately $16 \mathrm{msec}$ and then closed for the 26 msec interval during which the film is being transported. The brightness of the image on the film will depend greatly on the period in the lightning event during which the shutter is open. The brightness of the flash will be greatly attenuated if the shutter opens just as the electric discharge is ending. Individual lightning discharge events are often short in comparison with the $26 \mathrm{msec}$ interval during which the shutter is closed. As a consequence, it is probable that a significant fraction of the lightning events taking place in the field of view of the camera are not recorded on the film.

There is uncertainty in establishing the dimensions of the images on the lightning photographs. Because the camera was held by hand, and because no features such as the limb of the Earth are visible in any of the nocturnal pictures taken, the orientation of the camera with respect to the Earth is not known. In analyzing the pictures all that can be done is to establish a minimum scale for the photographs on the assumption that the camera is looking directly downward. If this were the case, then the scale of distance would be correct in both dimensions. However, the camera will probably seldom be looking vertically down. As a consequence, the scale will often vary widely over the plane of the photographs. The dimensions of lightning discharges may be underestimated by a factor of as much as two or more.

In the photographs that were taken at night the feature of primary interest is the development of lightning events that can be seen to progress frame by frame over large areas. We have found that the most satisfactory way of presenting the data in these lightning episodes is to project the image onto a piece of paper one frame at a time, and to outline the maximum extent of each luminous area with a pen or pencil. By this method a condensed view showing the time of occurrence and the location of each of the luminosities can be presented on a single figure.

The sequences of lightning activity taken during STS-2 over Africa are illustrated in this way in Figure 6. Those taken during STS-4 over Southern Brazil are shown in Figures 7 and 8. Episodes $C$ through $G$ were taken on 28 June at 23:20 GMT, and $\mathrm{H}$ and $\mathrm{I}$ the next day one orbit later at 00:57 GMT. The first luminous area to appear is designated with a 0 . Each successive area that develops in the lightning event is given a number showing how many milliseconds intervened after the first area appeared. Because no information is available on when the luminosity occurred during the 16-msec exposure of each frame of the film, there is an uncertainty in the assigned times of $\pm 8 \mathrm{msec}$.

It must be recognized that the indicated boundaries of the areas are based on subjective judgments of their maximum extent. The line of demarcation between the exposed area and the unexposed film is, of course, not sharp, so that the areas indicated are, to some extent, approximations. Undoubtedly, there are many lightning events that remain undetected because the luminosity they produced was below the threshold of detection.

In events in which the lightning pattern illuminating the clouds is clearly recognizable from one frame to the next, such as that illustrated in Figure 4 and in Figure 5, there is little ambiguity in ascertaining the growth or progression of the luminous area. 


\section{$\Im^{125}$}
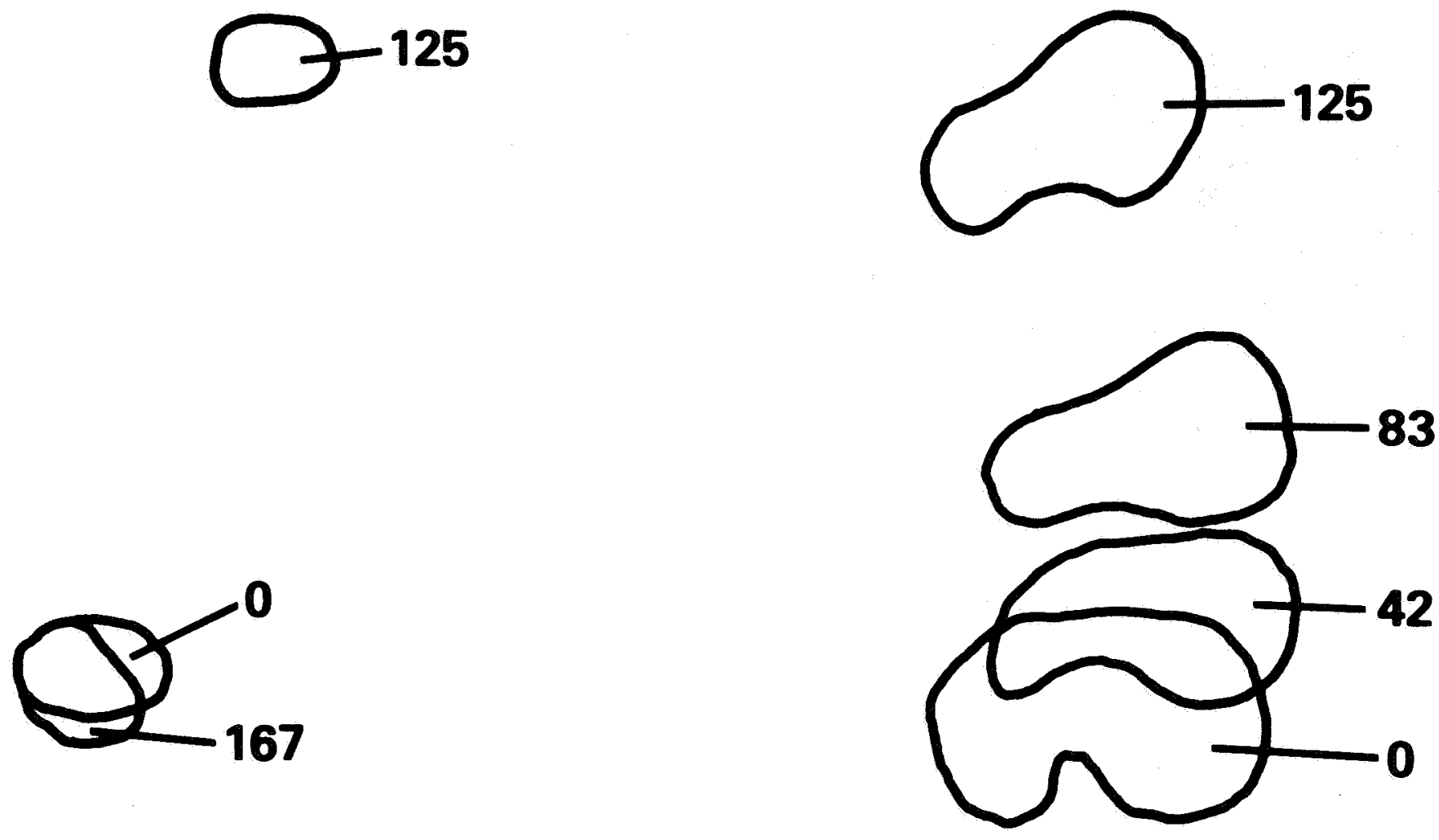

A

B

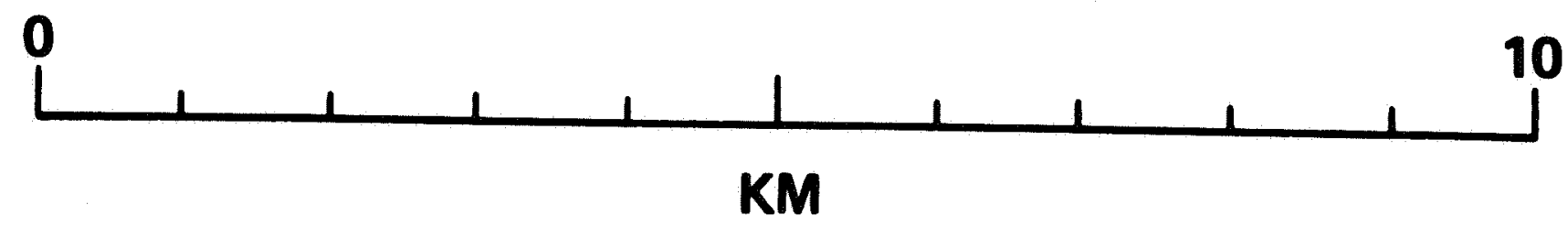

Figure 6. Lightning sequences $A$ and $B$ photographed by Astronaut Truly during STS-2. 

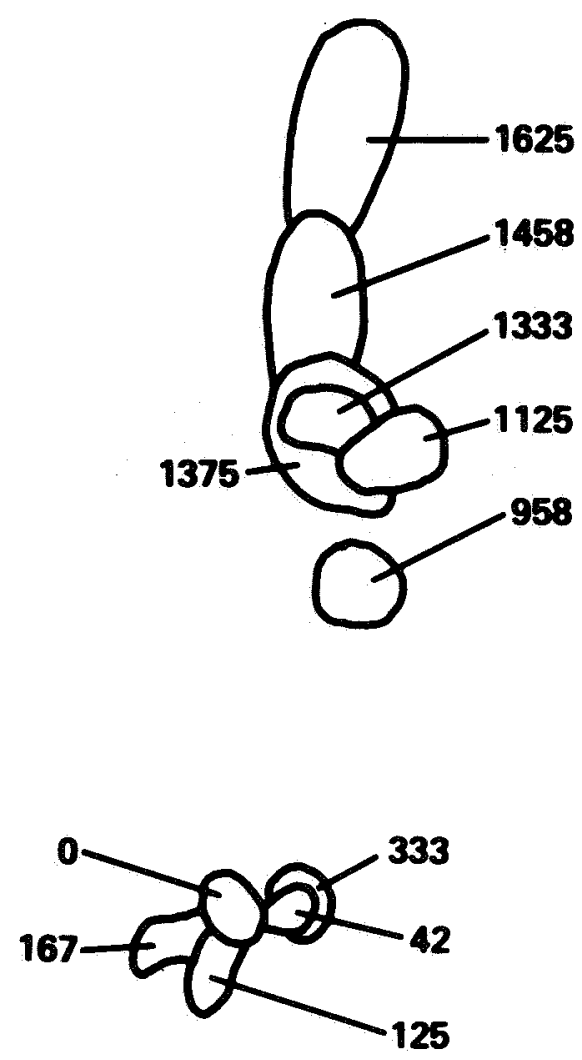

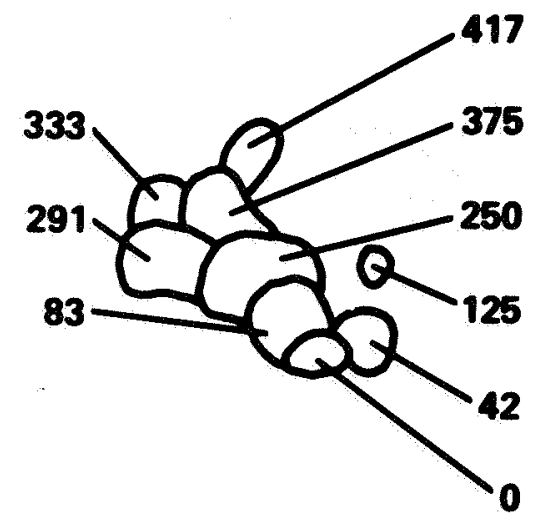

C

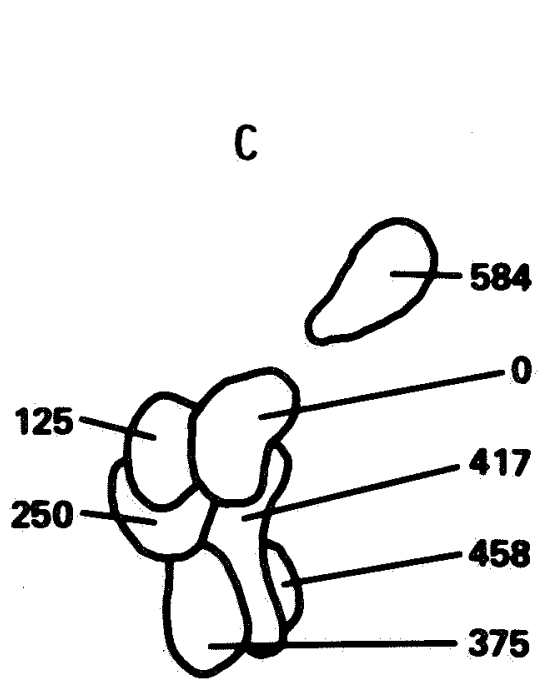

$\mathbf{E}$
D

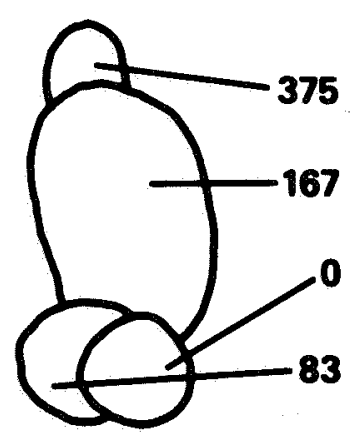

O-250

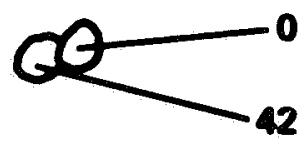

$\mathbf{F}$

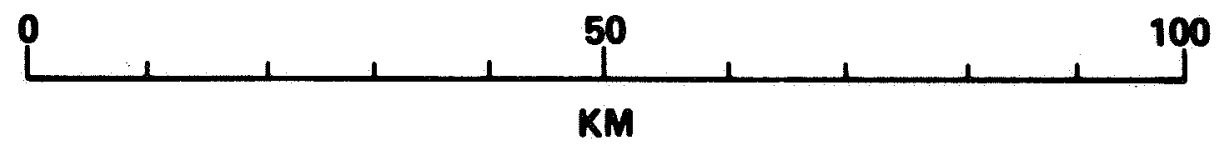

Figure 7. Lightning sequences C-F photographed by Astronaut Mattingly during STS-4. D illustrates the sudden, nearly simultaneous initiation of two lightning flashed at locations separated by more than $82 \mathrm{~km}$. 


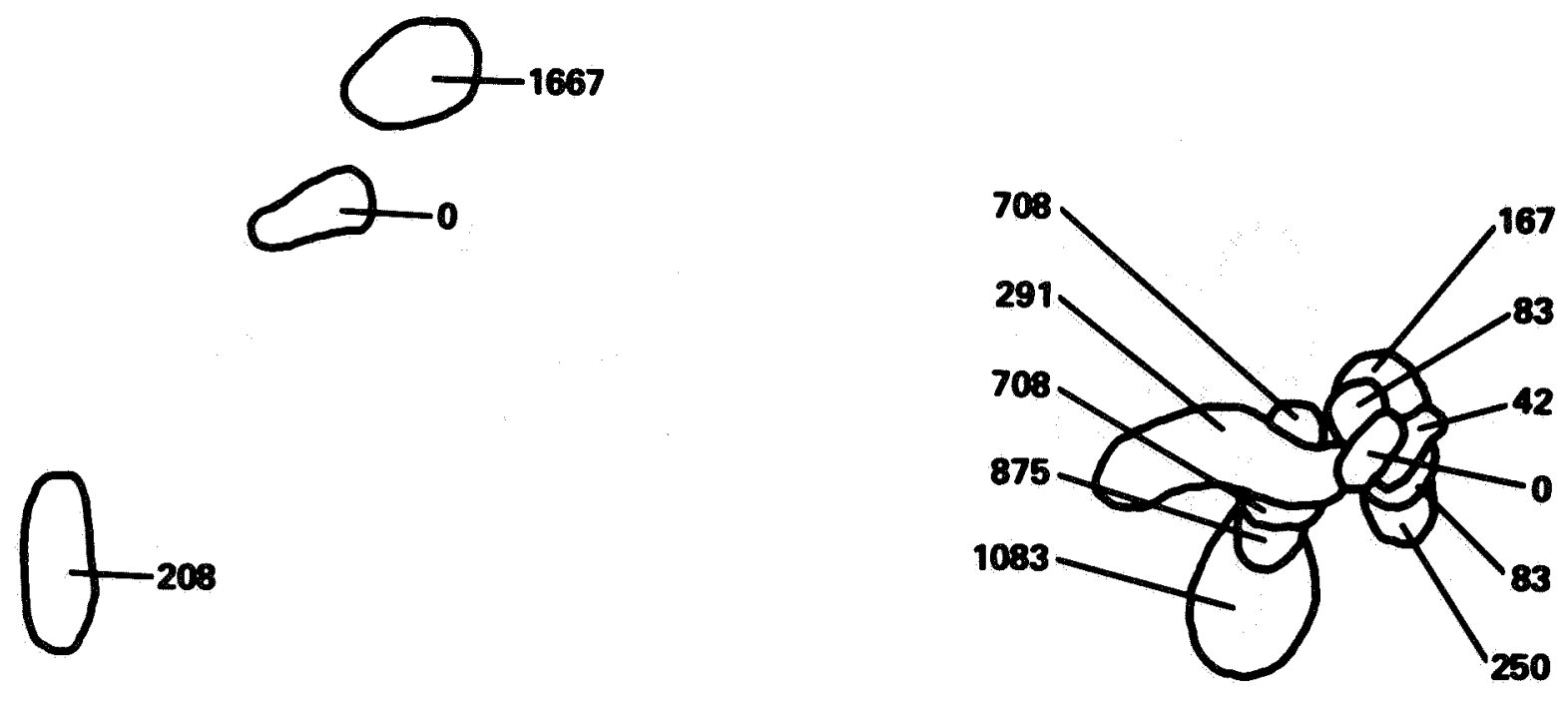

G

H
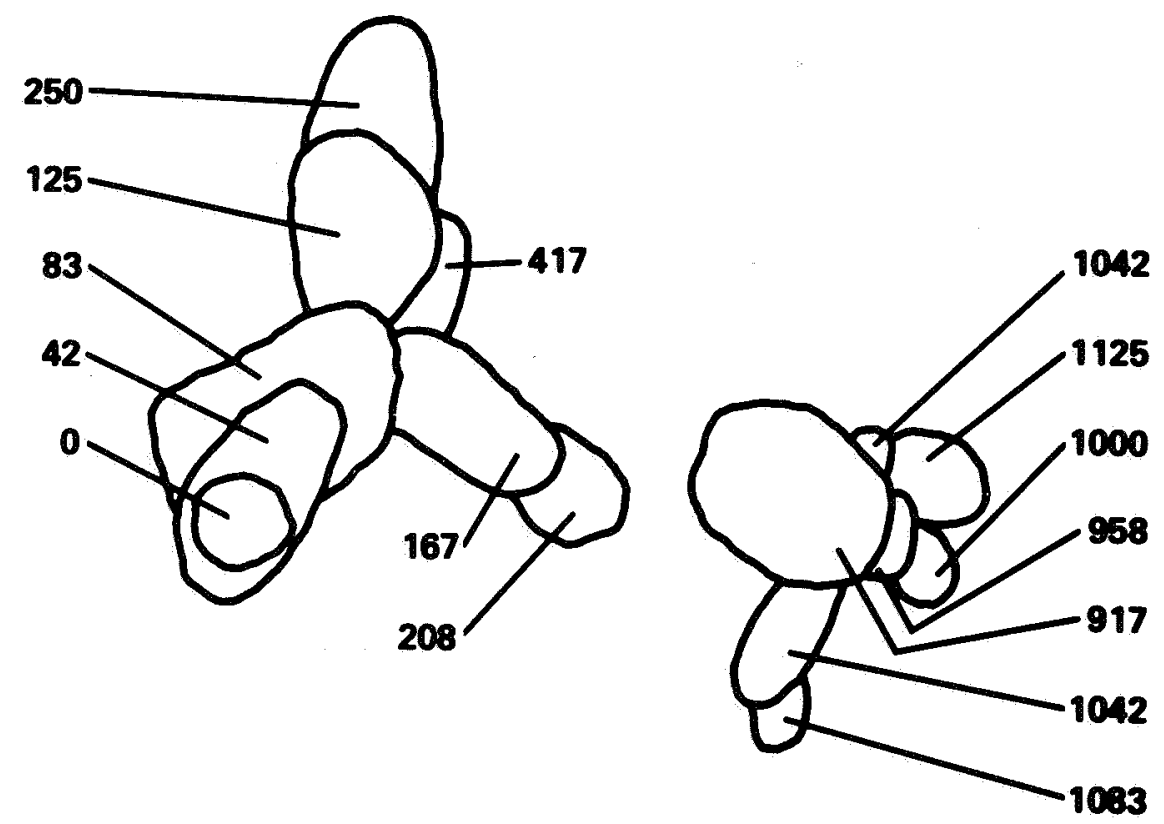

$1458-\mathcal{W}_{1750}^{1542}$

I

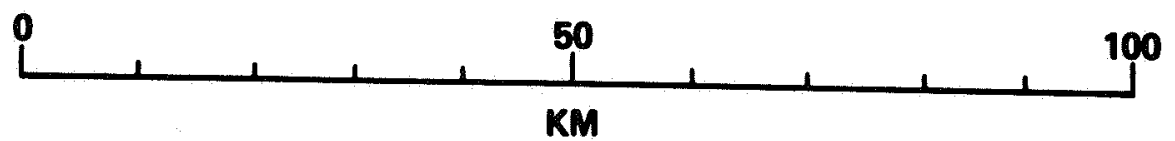

Figure 8. Lightning sequences G-I photographed by Astronaut Mattingly during STS-4. I illustrates formation of Y-shaped pattern shown in Figure 4 and subsequent discharges that took place. 
In other cases in which no distinctive repetitive pattern of the lightning or of the area illuminated by the lightning can be clearly perceived, such as is the case in most of the flashes shown in Figure 7, there is a further problem in interpreting the data. Changes in the position of the luminous area from one frame to another can be produced by causes other than the progression of the lightning discharge. Rapid changes of orientation of the hand-held camera with respect to the vehicle, changes in the orientation of the vehicle, and motions of the vehicle with respect to the thunderstorm, can all produce a displacement of the luminous areas on the film.

Examination of pictures of cloud features taken from the space Shuttle during daylight shows that camera movements at a rate of one tenth of a radian or more per second can sometimes occur. Should such motions take place during lightning photography, they would produce apparent motions of the order of $3 \times 10^{4} \mathrm{msec}^{-1}$ or more. The speed of the Space Shuttle is $8 \times 10^{3} \mathrm{msec}^{-1}$; therefore, the uncertainties in the measurements of lightning propagation arising from these causes could possibly be of the order of several times $10^{4} \mathrm{msec}^{-1}$.

\section{DISCUSSION}

Close inspection of the larger and brighter illuminated areas in the nocturnal photographs taken during STS- 4 with the lens in the wide-angle position shows structures on the scale of about $10 \mathrm{~km}$ that probably are cumuliform cloud tops. The pictures taken with the lens in the telephoto position during STS-6 are similar to those shown in photographs taken from U-2 aircraft [22] but not as detailed and do not resolve any lightning channels. With photographic equipment of greater resolving power, it should be possible to see even more structure in the cloud tops and even lightning channels.

The lightning sequences illustrated in Figures 6, 7, and 8 exhibit similarities suggesting that they may all have been formed in a similar way. Apparently under the influence of strong electrical stresses building up in the storm, dielectric breakdown of the air is initiated at some point and then spreads in various directions to produce the patterns shown in these figures.

It is possible to make estimates of the speeds of growth of the illuminated cloud pattern. If it is assumed that the displacements of the bright areas from frame to frame arise entirely from the progression of the luminous region through the cloud and that effects from the movements of the camera or the vehicle can be neglected, the results are as shown in Table 1. It must be remembered that because of the uncertainty in the scale of the figures, these estimates may be considerably less than the actual speed.

TABLE 1. SPEEDS OF GROWTH OF ILLUMINATED CLOUD PATTERNS FROM MOTION PICTURES TAKEN DURING STS-4

Lightning

Sequences

Max Speed

$10^{5}$

$\mathrm{msec}^{-1}$
A

B

C

D

E

$1.2 \quad 0.4$ $\begin{array}{lll}0.7 & 20 & 0.8\end{array}$
F

G

$\mathrm{H}$

I

3.0
2.0

0.7

2.0 
In sequence I where the initial luminous area persisted for almost half a second and could be used as a fixed reference, camera motions have little influence on the estimate of the speed of growth. In other cases, camera motions may be playing a significant role. In sequence $B$, there is such a similarity in the sizes and shapes of the four images it is possible that they may in fact be of the same cloud illuminated by repeated strokes and that the displacements are entirely the result of camera motion.

Inspection of Table 1 shows that, with the exception of sequence $D$, the propagation speeds range from 0.4 to $3 \times 10^{5} \mathrm{msec}^{-1}$. These values are similar to the value of 5-8 $\times 10^{4} \mathrm{msec}^{-1}$ that follows from Paul Weitz's statement about the flash he saw in Africa: "It went 100 to $150 \mathrm{~km}$ in a couple of seconds, but this is only an estimate." [14]. Within the limits of experimental error, these speeds are in agreement with those based on optical observations of the stepped leader [23] and on VHF measurements of lightning $[24,25,26]$.

The lightning event illustrated in sequence $\mathrm{D}$ is unusual in that not one, but two, luminous areas, which are separated by a distance of more than $82 \mathrm{~km}$, appear on the initial frame. A possible explanation for this situation is that a breakdown process first occurred in one of the locations and then spread to the other. In this event the minimum value for the speed of connection between the two areas is $20 \times 10^{5}$ $\mathrm{msec}^{-1}$, the value shown in the table. This speed is so great it appears likely that whatever is occurring is different from that taking place in the other 8 lightning events.

The sudden initiation of lightning at almost the same time in two widely separated places shown in sequence D suggests a phenomenon similar to that which has previously been observed by astronauts. For example, Gibson said in his description [10] that the lightning "could go off simultaneously, or near simultaneously, over a large distance. . .". Truly, in his debriefing, described two separated areas of frequent lighting in the Amazon Basin that appeared "to be talking to each other." Aside from a high speed ionization process communicating between the two areas, there are several other possible explanations for the nearly simultaneous discharges. Perhaps one of the discharges may be triggered by electric field changes or electromagnetic radiation produced by the other discharge. Possibly both discharges are being triggered by a third discharge that cannot be seen on the film. It must also be recognized that these simultaneous occurrences may be unrelated coincidences that occur entireliy by chance.

From analysis of further and more numerous observations it should be possible to determine whether it is probable that such separate lightning occurrences are somehow related. If they are, it will be of interest to see over how large a distance this relationship can exist.

The Y-shaped lightning discharge shown in the photographs in Figure 4 and in the upper left-hand corner of the patterns shown in sequence $I$ of Figure 8 is of special interest. The initial bright area in the first frame remains visible for almost a half-second, thus providing a fiducial point from which growth can be reckoned. This part of the discharge continues to be as bright or brighter than any other portion of the discharge during the entire period that the $\mathrm{Y}$-shaped pattern is visible. The persistence of this initial bright area suggests that it may be the position of the initial cloud-to-ground lightning stroke. In this event it is probable that the charge 
deposited within the cloud by this and successive strokes to ground raises the electric field above breakdown intensity and allows the discharge to propagate horizontally out into the cloud. By this process charge and electrical energy derived from a large area are brought together and conducted into the initial channel that remains connected to the ground. An extrapolation based on the assumption that a 10 coulomb discharge is capable of illuminating a single thunderstorm $10 \mathrm{~km}$ in diameter suggests that the discharge shown in Sequence I may have conveyed a charge as large as 500 coulombs to the ground. This discharge appears in many ways to be similar to the lightning event described by Workman, et al. [27]. If this interpretation is correct, certain characteristics in the development of a discharge as viewed from above can be used to identify it as a cloud-to-ground discharge.

Although, as is shown in Table 1, there is some consistency in the maximum rates at which the patterns grow, there is a puzzling, very wide variation not only in the speed, but in the direction of the pattern's development. Some patterns, such as the upper portion of sequence $\mathrm{C}$, show an orderly progression of the luminous area, but often this is absent. It is difficult to understand what is taking place in the sequence illustrated in Figure 4 . Why it is, after the development of the curved segment in the first four frames, that an arm begins to grow out of the middle of the segment? If these patterns represent the spread of a dielectric breakdown process, why doesn't the arm form at once? Why does it delay until the segment reaches its maximum development? Why does the direction of development rapidly change, sometimes by $180^{\circ}$ in a brief period of time? The manner in which these patterns develop suggests that a release of electrical energy in one portion of the cloud is increasing the electrical stresses in other parts of the cloud, thus triggering the development of a new breakdown process.

The maximum span of the discharges observed thus far, about $100 \mathrm{~km}$ in Sequences $C$ and $I$, is considerably smaller than the figure of 200 or $300 \mathrm{~km}$ estimated by Weitz. The maximum area encompassing a discharge, about $5 \times 10^{3} \mathrm{~km}^{2}$ in sequence $I$, is much smaller too than the figure of $10^{6} \mathrm{~km}^{2}$ estimated by Gibson. However, these differences are not surprising. The observations reported here were of a winter thunderstorm, in itself an unusual event, that was of only modest electrical activity as indicated by its low frequency of lightning discharges. There can be little doubt that in the future more intense storms will be photographed that will exhibit lightning events even larger than any that have been reported thus far. It is worth noting that the lightning activity in the Amazon Basin observed by astronaut Truly prior to the time the camera was unstowed on STS-2 was comparable in size to that reported by Gibson and Weitz.

\section{CONCLUSIONS}

It is encouraging to find that even this brief and modest effort to photograph lightning from the Space Shuttle has yielded interesting results. It has provided data showing that lightning events spread horizontally at speeds up to $10^{5} \mathrm{msec}^{-1}$ and can, in some cases, grow into discharge patterns that extend for $60 \mathrm{~km}$ or more. Because the data sample is small, comprising only a few dozen lightning flashes, it is difficult in some cases to draw firm conclusions. The first frame of one lightning sequence shows that discharges originated at two points $80 \mathrm{~km}$ apart in a $42 \mathrm{msec}$ time interval. It is unclear whether the two events are related or whether they occurred by chance. 
The results show that the Space Shuttle is particularly well suited for obtaining data on mesoscale lightning discharges that are too large to be photographed from the ground or even from a high altitude airplane.

Astronauts should be encouraged to continue photography of thunderstorm cloud formations and lightning using whatever cameras are available. There is no substitute for their demonstrated ability to recognize, and take pictures of interesting cloud structures and electrical discharges and to utilize the most appropriate focal length of lens and exposure. In the past astronauts have accumulated fascinating and useful photographs valuable to geologists, oceanographers and meteorologists. It should be possible to extend these activities on future flights to include, when feasible, the photography of thunderstorm formations by day and lightning at night. All of the conventional film and video cameras routinely carried on every flight can readily be used for this purpose.

A time exposure photograph of airglow taken by Astronaut Valery Ryumin from Salyut 6 [28] shows interesting lightning events similar to those reported here. It is to be anticipated that through further international cooperation it will eventually be possible to accumulate a wide diversity of photographs of lightning phenomena as observed from space.

Because of the many demands that are made on astronauts' time, it is unlikely that they will be free to photograph more than a small fraction of the thunderstorms and lightning displays that will be visible from their orbiting spacecraft. It appears feasible to enhance the rate of data acquisition by installation of equipment in the payload bay of the Space Shuttle that will automatically photograph lightning. Such equipment triggered by lightning signals picked up by a photocell could automatically record the time and take photographs of clouds and lightning and record the accompanying optical transients. Cameras in such equipment would be fixed with relation to the Shuttle. Since the position and the orientation of the vehicle are accurately known at all times, it will be possible to determine the location and dimension of storm clouds and lightning without the uncertainties that are often associated with photographs made with a hand-held camera.

The results thus far from this brief preliminary program of lightning observations conducted from the Space Shuttle show that a satellite in low orbit provides unique opportunities for the study of lightning activity on the mesometeorological scale. The data that have been obtained will contribute not only to the scientific understanding of thunderstorms, but also to the development of lightning detecting instrumentation that can be used on a satellite in geostationary orbit. Data from this vantage point will doubtless provide a new and revealing picture of lightning activity on a global scale. 


\section{REFERENCES}

1. Sparrow, J. G., and Ney, E. P.: Lightning Observations by Satellite. Nature, Vol. 232, 1971, pp. 540-541.

2. Turman, B. N.: Analysis of Lightning Data From DMSP Satellites. J. Geophys. Res., Vol. 83, 1978, pp. 5019-5024.

3. Radio Research Laboratories, Japan: World Distribution of Thunderstorm Activity Obtained from Ionosphere Sounding Satellite-B Observations June 1978 to May 1980. Available from Radio Research Laboratories, Ministry of Posts and Telecommunications, 10-2 Nukui-Kitamachi 4-Chome, Koganei-shi, Tokyo 184, Japan, 57 pp, 1981.

4. Orville, R. E.: Global Distribution of Midnight Lightning - September to November 1977. Mon. Wea. Rev., Vol. 109, 1981, pp. 391-395.

5. Taylor, W. W. L., Scarf, F. L., Russell, C. T., and Brace, L. H.: Evidence for Lightning on Venus. Nature, Vol. 279, 1979, pp. 614-616.

6. Cook, A. F., Duxbury, T. C., and Hunt, G. E.: First Results on Jovian Lightning. Nature, Vol. 280, 1979, p. 794.

7. Ksanfomaliti, L. V.: Discovery of Frequent Lightning Discharges in Clouds on Venus. Nature, Vol. 284, 1980, pp. 244-246.

8. Scarf, F. L., Taylor, W. W. L., Russell, C. T., and Brace, L. H.: Lightning on Venus Orbiter Detection of Whistler Signals. J. Geophys. Res., Vol. 85, 1980, pp. 8158-8166.

9. Kaiser, M. L., Connerney, J. E. P., and Desch, M. D.: Atmospheric Storm Explanation of Saturnian Electrostatic Discharges. Nature, Vol. 303, 1983, pp. 50-53.

10. Cooper, H. S. F., Jr.: Life in a Space Station II. New Yorker Magazine, 6 SEP 76, 1976, pp. 34-70.

11. Ligda, M. G. H.: The Radar Observation of Lightning. J. Atmos. Terr. Phys., Vol. 9, 1956, pp. 329-346.

12. Brook, M., and Vonnegut, B.: Visual Confirmation of the Junction Process in Lightning Discharges. J. Geophys. Res., Vol. 65, 1960, pp. 1302-1303.

13. Mazur, V.: Associated Lightning Discharges. Geophys. Res. Lett., Vol. 9, 1982 , pp. 1227-1230.

14. Vonnegut, B.: Lightning - Observation from Space. Weather, Vol. 34, 1979, p. 291.

15. Taranik, J. V., and Settle, M.: Space Space Shuttle: A New Era in Terrestrial Remote Sensing. Science, Vol. 214, 1981, pp. 619-626. 
16. Settle, M., and Taranik, J. V.: Use of the Space Space Shuttle for Remote Sensing Research: Recent Results and Future Prospects. Science, Vol. 218, 1982, pp. 993-995.

17. Vonnegut, B.: Top Weather Event of 1981 - Flight of the Space Shuttle. Weatherwise, Vol. 35, 1982, pp. 27-29.

18. Vonnegut, B., Vaughan, O. H., Jr., and Brook, M.: Photographs of Lightning from the Space Shuttle. Bull. Amer. Meteor. Soc., Vol. 64, 1983, pp. 150-151.

19. Griffiths, R. F., and Vonnegut, B.: Tape Recorder Photocell Instrument for Detecting and Recording Lightning Strokes. Weather, Vol. 30, 1975, pp. 254257.

20. Vonnegut, B., and Passarelli, R. E., Jr.: Modified Cine Sound Camera for Photographing Thunderstorms and Recording Lightning. J. Appl. Meteor., Vol. 17, 2978, pp. 1079-1081.

21. Brook, M., Tennis, R., Rhodes, C., Krehbiel, P., Vonnegut, B., and Vaughan, O. H., Jr.: Simultaneous Observations of Lightning Radiations from Above and Below Clouds. Geophys. Res. Letters, Vol. 7, 1980, pp. 267-270.

22. Brook, M., Rhodes, C., Vaughan, O. H., Jr., Orville, R. E., and Vonnegut, B.: Observations of Thunderstorm Electrical Activity at Night Looking Down from a High Altitude Airplane. Manuscript in preparation, 1984.

23. Uman, M. E.: Lightning. McGraw-Hill Book Co., New York, 1969.

24. Rustan, P. L., Uman, M. A., Childers, D. G., Beasley, W. H., and Lennon, C. L.: Lightning Source Locationa from VHF Radiation Data for a Flash at Kennedy Space Center. J. Geophys. Res., Vol. 85, 1980, pp. 4893-4903.

25. Proctor, D. E.: VHF Radio Pictures of Cloud Flashes. J. Geophys. Res., Vol. 86,1981, pp. 4041-4071.

26. Hayenga, C. O., and Warwick, J. W.: Two-Dimensional Interferometric Positions of VHF Lightning Sources. J. Geophys. Res., Vol. 86, 1981, pp. 74517462 .

27. Workman, E. J., Brook, M., and Kitagawa, N.: Lightning and Charge Storage. J. Geophys. Res., Vol. 65, 1960, pp. 1513-1517.

28. Koutchmy, S., and Nikol'skij, G. M.: The Night Sky from Salyut. Sky \& Tel.; Vol. 65, 1983, pp. 23-25. 


\begin{tabular}{|c|c|}
\hline \begin{tabular}{l|l} 
2. GOVERNMENT ACCESSION NO. \\
\end{tabular} & 3. RECIPIENT'S CATALOG NO. \\
\hline \multirow{2}{*}{$\begin{array}{l}\text { 4. TITLE AND SUBTITLE } \\
\text { MESOSCALE OBSERVATIONS OF LIGHTNING FROM SPACE SHUTTLE }\end{array}$} & $\begin{array}{l}\text { 5. REPORT DATE } \\
\text { September } 1984\end{array}$ \\
\hline & 6. PERFORMING ORGANIZATION CODE \\
\hline 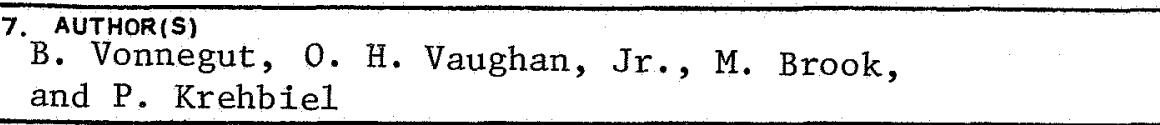 & 8. PERFORMING ORGANIZATION REPORT \# \\
\hline \multirow{3}{*}{$\begin{array}{l}\text { 9. PERFORMING ORGANIZATION NAME AND ADDRESS } \\
\text { George C. Marshall Space Flight Center } \\
\text { Marshall Space Flight Center, Alabama } 35812\end{array}$} & $\begin{array}{l}\text { 10. WORK UNIT NO. } \\
\text { M-461 }\end{array}$ \\
\hline & 11. CONTRACT OR GRANT NO. \\
\hline & 13. TYPE OF REPOR'i \& PERIOD COVERED \\
\hline \multirow{2}{*}{$\begin{array}{l}\text { 12. SPONSORING AGENCY NAME AND ADORESS } \\
\text { National Aeronautics and Space Administration } \\
\text { Washington, D.C. } 20546\end{array}$} & Technical Memorandum \\
\hline & 14. SPONSORING AGENCY CODE \\
\hline \multicolumn{2}{|c|}{$\begin{array}{l}\text { 15. SUPPLEMENTARY NOTES } \\
\text { B. Vonnegut: State University of New York at Albany, New York. } \\
\text { O. H. Vaughan, Jr.: George C. Marshall Space Flight Center, Alabama. } \\
\text { M. Brook and P. Krehbiel: New Mexico Institute of Mining and Technology, } \\
\text { Socorro, New Mexico. }\end{array}$} \\
\hline
\end{tabular}

16. ABSTRACT

Motion pictures have been taken at night by astronauts on the space shuttle showing lightning discharges that spread horizontally at speeds of $10^{5} \mathrm{msec}^{-1}$ for distances over $60 \mathrm{~km}$. Tape recordings have been made of the accompanying optical pulses detected with a photocell optical system. The observations show that lightning is often a mesoscale phenomena that can convey large amounts of electric charge to earth from an extensive cloud system via a cloud-to-ground discharge.

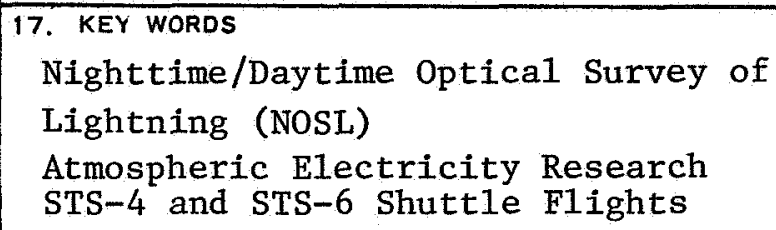

